\title{
SISTEMA GEOVITÍCOLA PARA A PRODUÇÃO DE UVAS PARA VINHO NA REGIÃO DO CIRCUITO DAS FRUTAS-SP ${ }^{1}$
}

\author{
LUDMILA BARDIN-CAMPAROTTO², MÁRIO JOSÉ PEDRO JÚNIOR ${ }^{3}$, \\ GABRIEL CONSTANTINO BLAIN ${ }^{4}$, JOSÉ LUIZ HERNANDES ${ }^{5}$
}

RESUMO - Nos últimos anos, tem-se observado aumento na produção de uvas destinadas à elaboração de vinhos na região do Circuito das Frutas, Estado de São Paulo, promovido principalmente pelo turismo rural. O objetivo deste trabalho foi caracterizar o potencial climático dessa região para produção de uvas para vinho, utilizando o Sistema de Classificação Climática Multicritérios Geovitícola, baseado nos índices biometeorológicos: heliotérmico, de frio noturno e de seca, considerando as safras de verão e de inverno. Para a safra de verão, foram identificadas áreas com clima quente, úmidas e com noites quentes, situadas na região oeste do Circuito das Frutas; na região centro-leste, as noites foram caracterizadas como temperadas e, nas áreas de altitudes mais elevadas, o clima encontrado foi o temperado quente, sem período seco e com noites temperadas. Para a safra de inverno, os valores de umidade mantiveram-se elevados, com as classes climáticas variando entre quente, temperado quente e temperado, com noites muito frias. O Circuito das Frutas apresentou características que podem favorecer a obtenção de uvas para vinhos brancos e espumantes. Termos para indexação: viticultura, clima, Sistema CCM, zoneamento, Vitis vinifera.

\section{GEOVITICULTURE SYSTEM FOR GRAPEWINE PRODUCTION IN THE 'FRUIT CIRCUIT’ REGION, STATE OF SÃO PAULO, BRAZIL}

\begin{abstract}
In recent years, it has been seen an increase in the wine grape production in the 'Fruit Circuit region, in the State of São Paulo. It is a region with great attractions associating tourism and wine production. The objective of this study was to evaluate the climatic potential of this region for wine grape production by means of the Multicriteria Climatic Classification System (Geoviticulture MCC System). The MCC System is based on three climatic indexes: heliothermal index, cool night index and dryness index and, it was calculated for the summer and winter growing seasons. During the summer growing season, the MCC System indicated that some areas in western of the region are warm, humid and have warm nights. The east-central area has a temperate night and in areas with higher altitude the climate found was warm temperate, without dry periods and temperate nights. For the winter growing season, the MCC System indicated high moisture values, with climatic classes ranging from hot, warm temperate and temperate. All these classes comprise very cold nights. The 'Fruit Circuit region showed humid condition during both summer and winter growing seasons.
\end{abstract}

Index terms: viticulture, climate, MCC System, zoning, Vitis vinifera.

\footnotetext{
${ }^{1}$ (Trabalho 377-13). Recebido em: 08-10-2013. Aceito para publicação em: 25-03-2014.

${ }^{2}$ Eng. Amb. Dra., Pós-Doutoranda, Centro de Ecofisiologia e Biofísica, IAC, Caixa Postal 28, Campinas, SP, Brasil. E-mail: ludmila_bardin@ yahoo.com.br. Bolsista FAPESP (Pós-Doutorado).

${ }^{3}$ Eng. Agr. Dr., PqC Centro de Ecofisiologia e Biofísica, IAC, CP 28, Campinas, SP, Brasil. E-mail: mpedro@iac.sp.gov.br. Bolsista $\mathrm{CNPq}$

${ }^{4}$ Eng. Agrícola Dr., PqC Centro de Ecofisiologia e Biofísica, IAC, CP 28, Campinas, SP, Brasil. E-mail: gabriel@iac.sp.gov.br

${ }^{5}$ Biólogo MS., PqC Centro de Fruticultura, IAC, Jundiaí, SP, Brasil. E-mail: jlhernandes@iac.sp.gov.br
} 


\section{INTRODUÇÃO}

A produção de uvas destinadas à elaboração de vinho na região do Polo Turístico do Circuito das Frutas, no Estado de São Paulo, tem aumentado nos últimos anos, sendo o turismo rural o principal meio de promover este produto. O enoturismo da região ocorre com a visitação a vinícolas e parreirais, associando a degustação do produto às atividades culturais, como curso sobre vinhos e gastronomia (SATO et al., 2010; VERDI et al., 2011).

Dentro deste contexto, o zoneamento é utilizado na identificação do potencial climático de determinada área para o desenvolvimento da viticultura (MARIN et al., 2008). Para Pommer et al. (2009), a diversidade climática existente nas regiões vitícolas influencia as diferenças encontradas nos produtos, na qualidade e na tipicidade dos vinhos. Considerando as interações entre o clima, os requisitos da videira e seu ciclo de crescimento, vários índices bioclimáticos têm sido propostos como ferramenta de zoneamento na indicação de áreas adequadas à produção de uvas para vinho (TONIETTO; CARBONNEAU, 2004; BOIS; PÉRARD, 2009; SANTOS et al., 2012).

Tonietto e Carbonneau (2004) definiram um procedimento utilizado na classificação do clima vitícola de diferentes regiões do mundo. Este é definido como sistema de classificação climática multicritério geovitícola (Sistema CCM Geovitícola ou Sistema Geovitícola), sendo composto por: Índice Heliotérmico (IH), que de acordo com Carey e Bonnardot (2004) influencia o aroma do vinho; o Índice de Frio Noturno (IF), relacionado à intensidade do aroma do vinho e à coloração do mosto de variedades tintas (CARBONNEAU et al., 2007) e o Índice de Seca (IS), que indica a disponibilidade hídrica do solo, tendo relação com o amadurecimento das uvas e com a qualidade do vinho.

Tonietto et al. (2012) utilizaram o sistema CCM para caracterizar o clima vitícola e a tipicidade dos vinhos em diferentes países Ibero-americanos, como Argentina, Bolívia, Brasil, Chile, Cuba, Espanha, México, Peru e Portugal. No Brasil, trabalhos semelhantes foram desenvolvidos: Tonietto et al. (2006) para o Estado de Minas Gerais; Conceição e Tonietto (2005) para a região Norte Fluminense e Pommer et al. (2009) para o município de Campos dos Goytacazes, Rio de Janeiro.

O Estado de São Paulo, segundo maior produtor nacional de uva, tem buscado reestruturar, melhorar e expandir seu setor vitivinícola. Nesse contexto, Marin et al. (2008) desenvolveram o zoneamento pedoclimático da viticultura paulista, avaliando o potencial produtivo para uvas destinadas à elaboração de vinhos finos, utilizando o sistema CCM. Os resultados evidenciaram melhor potencial vitícola para a produção de outono-inverno, identificando áreas com clima vitícola similar a regiões produtoras de vinhos no Uruguai, França e à região Sul do Brasil. Entretanto, deve-se ressaltar que Marin et al. (2008) consideraram dois ciclos de produção: primavera-verão (outubro a março) e outono-inverno (abril a setembro). Os produtores da região do Circuito das Frutas normalmente têm utilizado os seguintes ciclos de produção: agosto a janeiro, safra de verão; e janeiro a junho, safra de inverno (ALARCON et al., 2010).

Dessa forma, considerando a importância da viticultura para o Circuito das Frutas, o objetivo deste trabalho foi caracterizar o potencial climático dessa região para produção de uvas para vinho, utilizando o Sistema CCM Geovitícola, durante as safras de verão e inverno.

\section{MATERIAL E MÉTODOS}

A região de estudo é compreendida pelos municípios de Indaiatuba, Itupeva, Itatiba, Jarinu, Jundiaí, Louveira, Valinhos, Vinhedo, Morungaba e Atibaia, estando localizada entre as coordenadas geográficas $22^{\circ} 50^{\prime}$ e $23^{\circ} 20^{\prime}$ sul e $46^{\circ} 25^{\prime}$ e $47^{\circ} 18^{\prime}$ oeste, com área aproximada de $2.386 \mathrm{~km}^{2} \mathrm{e}$ altitude variando entre 500 e $1.400 \mathrm{~m}$.

Para identificação de áreas adequadas à produção de uva para vinho, considerando as safras de verão (agosto a janeiro) e de inverno (janeiro a junho), foi aplicado o sistema de classificação climática multicritério, Sistema CCM Geovitícola (TONIETTO; CARBONNEAU, 2004), composto pelos índices heliotérmico, de frio noturno e de seca, como segue:

a) Índice Heliotérmico (IH): desenvolvido por Huglin (1978), estima o potencial heliotérmico de uma região específica, sendo expresso por:

$$
\mathrm{IH}=\sum_{\text {cofheita }}^{\text {poda }} \frac{[(\text { Tmed }-10)+(T \max -10)]}{2} * \mathrm{k}
$$

em que: Tmed $=$ temperatura média do ar $\left({ }^{\circ} \mathrm{C}\right)$; Tmáx $=$ temperatura máxima do $\operatorname{ar}\left({ }^{\circ} \mathrm{C}\right)$ e $\mathrm{k}=$ coeficiente comprimento do dia (no caso da latitude de São Paulo, considera-se k=1,0).

b) Índice de Frio Noturno (IF): índice desenvolvido para informar as condições térmicas relativas ao frio noturno, para o período de maturação da uva (TONIETTO, 1999). Neste trabalho, este período corresponde aos 30 dias que antecedem a colheita da uva. 


$$
\mathrm{IF}=\mathrm{Tn}_{\text {mês maturação }}
$$

em que: $\operatorname{Tn}_{\text {mês maturação }}=$ temperatura mínima noturna $\left({ }^{\circ} \mathrm{C}\right)$ do mês de maturação (média das mínimas do mês).

c) Índice de Seca (IS): informa a disponibilidade hídrica do solo.

Para a determinação do IS, considerou-se o método proposto por Tonietto e Carbonneau (2004), calculado para cada mês do ciclo produtivo, de acordo com a Eq. 3 e utilizou-se do método de Thornthwaite no cálculo da evapotranspiração potencial (ETP).

$$
\mathrm{w}=\mathrm{wo}+\mathrm{P}-\mathrm{TV}-\mathrm{ES}
$$

em que: Wo $=$ reserva hídrica potencial do solo $(200 \mathrm{~mm}) ; \mathrm{P}=$ precipitação pluvial $(\mathrm{mm})$; TV = transpiração potencial do vinhedo, e ES = evaporação direta do solo $(\mathrm{mm})$. De acordo com Tonietto e Carbonneau (2004), os valores de TV e ES foram obtidos com base nos valores de ETP. O valor de IS corresponde ao valor de $\mathrm{W}$ do último mês do ciclo produtivo.

A interpretação do IH, IF e IS, segundo Tonietto e Carbonneau (2004), encontra-se na Tabela 1.

O cálculo dos índices IH e IF foi realizado para os dez municípios que compõem o Circuito das Frutas, utilizando estimativas de temperatura máxima, mínima e média do ar, obtidas a partir de equações desenvolvidas por Bardin et al. (2010a) para a região do Circuito das Frutas, baseadas em altitude e latitude. Estas equações também foram utilizadas na elaboração de mapas raster de temperatura necessários para a espacialização dos índices IH e IF, aplicando-se as equações 1 e 2 em ambiente SIG (sistema de informação geográfica), software “ArcMap9.0”. O modelo digital de elevação do terreno (MDE) utilizado é o disponibilizado pelo Instituto Nacional de Pesquisas Espaciais - INPE (http://www.dsr.inpe.br/topodata/acesso.php), com resolução espacial de 30 m (VALERIANO, 2008). Para a obtenção do valor de IS foi calculada a ETP mensal (THORNTHWAITE, 1948) para cada município do Circuito das Frutas e gerada uma imagem raster com os valores de IS obtidos para a região. A espacialização final da combinação dos três índices que compõem o Sistema CCM Geovitícola foi realizada cruzando as três imagens raster obtidas para cada índice, fornecendo assim o clima vitícola para a região do Circuito das Frutas, para os dois períodos de produção considerados, safra de verão (agosto a janeiro) e safra de inverno (janeiro a junho).

A comparação do clima vitícola da região do Circuito das Frutas com as demais regiões produtoras mundiais foi realizada por meio da consulta na base de dados mundial do Sistema CCM Geovitícola (http://www.cnpuv.embrapa.br/tecnologias/ccm/ consulta.php).

\section{RESULTADOS E DISCUSSÃO}

A caracterização climática do Circuito das Frutas levou em consideração dois períodos distintos, a safra de verão, com produção entre agosto e janeiro, e a safra de inverno, entre janeiro e junho, salientando-se que esta condição é diferente da considerada por Marin et al. (2008) na caracterização climática do Estado de São Paulo. De maneira geral, o IH variou entre 2.490 e 2.770 para a safra de verão e entre 2.420 e 2.590 para a safra de inverno (Figura 1a). Os municípios situados a oeste do Circuito das Frutas apresentaram valores de IH mais elevados comparados aos situados na região leste, devido às temperaturas mais altas na região de Indaiatuba e Itupeva, conforme observado por Bardin et al. (2010a). Com base na classificação proposta por Tonietto e Carbonneau (2004), para a safra de verão, os valores de IH (Figura 1a) caracterizaram toda a região do Circuito das Frutas como sendo de clima quente $(\mathrm{IH}+2)$. Para a safra de inverno, apesar de os valores de IH terem sido inferiores aos observados para a safra de verão, a classe de clima vitícola manteve-se como sendo $\mathrm{IH}+2$. Ainda para a safra de inverno, observou-se que, nos municípios de Itatiba, Jarinu e Atibaia, os valores de IH ficaram próximos a 2.400 , valor limite entre as classes consideradas temperada quente $(\mathrm{IH}+1)$ e quente (IH+2). De acordo com Marin et al. (2008), regiões com climas $\mathrm{IH}+1$ ou $\mathrm{IH}+2$ não apresentam restrição à maturação de qualquer variedade. Dessa forma, os resultados apresentados na Figura 1a permitem inferir a inexistência de restrição climática, ligada à temperatura atmosférica, para a maturação das uvas no Circuito das Frutas.

Considerando o IF (Figura 1b), que segundo Tonietto et al. (2006) influencia na expressão do potencial de cor e aroma, verificou-se, para a safra de verão, que as temperaturas mínimas noturnas variaram entre 17,6 e $18,7^{\circ} \mathrm{C}$. Foram observadas áreas com noites temperadas (IF-1) nos municípios de Morungaba, Itatiba, Jarinu e Atibaia, e áreas com noites quentes (IF-2) nos demais municípios. Durante a safra de inverno, as temperaturas diminuíram ao longo do ciclo produtivo, sendo observados valores entre 10,3 e $11,5^{\circ} \mathrm{C}$ (Figura 1 b). Na região do Circuito 
das Frutas, foram observadas temperaturas mínimas noturnas durante a safra de inverno, classificadas pela Tabela 1 como noites muito frias ( $\mathrm{IF}+2)$. Nesse caso, segundo Marin et al. (2008), a garantia de condições heliotérmicas necessárias para a maturação torna-se dependente do IH.

Os resultados obtidos por meio da equação 3 (Figura 1c) indicaram que o Circuito das Frutas apresenta excesso hídrico no período de maturação/ colheita para a safra de verão, sendo os valores de IS superiores a $150 \mathrm{~mm}$ em todos os municípios. Essa condição climática é similar à observada por Westphalen e Maluf (2000) para o cultivo da Vitis vinifera L. no Rio Grande do Sul. Com isto, considera-se que a região possui clima úmido, sendo classificada, de acordo com Tonietto e Carbonneau (2004), como IS-2. Dessa forma, verifica-se que a colheita da safra de verão ocorre em período com elevada temperatura e umidade. Essa condição tende a potencializar problemas fitossanitários e colheitas com bagas ainda não maduras (MOTA et al., 2010). Este resultado corrobora o risco climático de ocorrência de doenças fúngicas apresentado por Bardin et al. (2010b), para a videira 'Niagara Rosada' na região do Circuito das Frutas. Segundo esses autores, a poda realizada em agosto favorece que o ciclo produtivo apresente risco de ocorrência de doenças fúngicas de até $75 \%$, para algumas áreas do Circuito das Frutas.

Antes de analisar os valores de IS observados durante a safra de inverno, é interessante ressaltar que, a fim de obter um vinho de melhor qualidade, os viticultores têm efetuado, nos meses de janeiro e fevereiro, a denominada "poda extemporânea", com o objetivo de realizar a colheita em época coincidente com a estação seca regional (AMORIN et al., 2005; MOTA et al., 2006; FÁVERO et al., 2008). Nesse sentido, os resultados apresentados na Figura 1c descrevem uma diminuição nos valores de IS entre as safras de verão e inverno. Entretanto, os mesmos permanecem acima de $150 \mathrm{~mm}$ nas duas safras.

A combinação dos índices IH, IF e IS, como proposto pelo Sistema CCM Geovitícola (Figuras 2 e 3), destacou agrupamentos climáticos distintos e, consequentemente, diferentes áreas para a produção de uvas destinadas à elaboração de vinhos, ao longo dos dois ciclos produtivos. Para a safra de verão (Figura 2), foram identificados quatro diferentes climas vitícolas. O clima da parte oeste do Circuito das Frutas (30\% da área de estudo) foi classificado como quente, com noites quentes, e úmido $(\mathrm{HI}+2$; IF-2; IS-2), apresentando similaridade climática com as regiões centro, norte e oeste do Estado de São Paulo, conforme observado por Marin et al.
(2008). A região centro-leste, representando $52 \%$ da região, enquadrou-se no grupo climático (HI+2; IF-1; IS-2), não catalogado na base de dados do Sistema CCM Geovitícola, sendo esta área quente, úmida e com noites temperadas. Na Figura 2, são também observadas áreas (14\% da região do estudo) com clima temperado quente, com noites temperadas e sem período seco (HI+1; IF-1; IS-2), apresentando similaridade climática com as regiões da Serra do Sudeste (Encruzilhada do Sul) e Serra Gaúcha (Vale dos Vinhedos). Nas regiões mais elevadas de Jundiaí e Atibaia, as condições observadas são de clima vitícola temperado, úmido e com noites temperadas (HI-1; IF-1; IS-2), sendo comparadas à região de Beli Kriz, na Eslovênia. Entretanto, considerando que essas áreas estão situadas nos topos de serras e morros, deve-se verificar a legislação de uso agrícola da terra.

Para a safra de inverno (Figura 3),também foram observados quatro diferentes climas vitícolas, sendo os mesmos distintos dos observados para a safra de verão. Na região centro-oeste e partes dos municípios de Itatiba, Jarinu e Atibaia, destacouse o clima vitícola quente (HI+2), úmido (IS-2) e com noites muito frias (IF+2). Segundo Tonietto e Carbonneau (2004), a síntese de antocianinas e precursores de aroma é favorecida pelo amadurecimento das bagas em regiões com baixa temperatura noturna. No entanto, o IS indica que essa área do Circuito das Frutas apresenta um clima mais úmido do que as regiões acima citadas. Condição também de elevada umidade (IS-2), com noites muito fritas $(\mathrm{IF}+2)$, mas com clima temperado quente $(\mathrm{HI}+1)$, foi observada nas regiões mais elevadas entre Morungaba e Itatiba, Valinhos e Vinhedo, Itatiba, Jarinu, Jundiaí e Atibaia. Condição similar a esse último tipo climático, mas com clima temperado (HI1), é observada nas regiões mais elevadas de Jundiaí e Atibaia. Essa classificação é semelhante à encontrada na região de Macon, na França. De acordo com Jackson e Lombard (1993), temperaturas elevadas durante o dia, associadas a noites frias, reduzem o pH e a degradação dos ácidos orgânicos. Além disso, resultados obtidos por Mota et al. (2010), em estudo realizado no sul de Minas Gerais para diferentes variedades viníferas, indicam que, durante a safra de inverno, os valores de $\mathrm{pH}$, sólidos solúveis, açúcares nas bagas, antocianinas e fenólicos totais nas cascas e sementes tendem a ser mais elevados do que os valores obtidos para a safra de verão, além de serem produzidas bagas com maior teor de ácido málico no mosto. Santos et al. (2011a) também obtiveram maior intensidade de cor e valores mais elevados de antocianinas, polifenóis totais, taninos e sólidos 
solúveis para a cultivar Ruby Cabernet, na safra de inverno. Ainda, na região do Circuito das Frutas, Santos et al. (2011b) relataram para a cultivar Syrah valores mais elevados de antocianinas, polifenóis totais e sólidos solúveis; entretanto, valores mais baixos de taninos, comparando-se a safra de inverno com a de verão. Para a safra de inverno, são também verificadas condições de clima temperado (Tabela 1) nas regiões com altitude mais elevada nos municípios de Jundiaí e Atibaia. Essa condição favorece sistemas de produção vitícola de clima tropical e subtropical, caracterizados por invernos mais frios e temperaturas mais amenas durante o ciclo vegetativo.

De maneira geral, a utilização do Sistema
CCM para caracterizar a região do Circuito das Frutas permitiu verificar diferenças entre as áreas mais elevadas quando considerado o IH. No entanto, os índices IF e IS não mostraram diferenças regionais ao longo da mesma safra. Na comparação entre as safras, as maiores diferenças foram observadas para o IF. As características climáticas observadas no Circuito das Frutas dificultam, segundo Marin et al. (2008), a maturação das bagas e acentuam o risco de infecções fúngicas. De acordo com Tonietto e Carbonneau (2004), essas características podem favorecer a obtenção de uvas para vinhos brancos e espumantes.

TABELA 1 - Classes de clima vitícola, siglas e intervalos de classes para o Índice Heliotérmico (IH), Índice de Frio Noturno (IF) e Índice de Seca (IS), segundo Tonietto e Carbonneau (2004).

\begin{tabular}{cccc}
\hline Índice climático vitícola & Classes de clima & Sigla & Intervalo de classe \\
\hline & Muito frio & $\mathrm{IH}-3$ & $\mathrm{IH} \leq 1500$ \\
& Frio & $\mathrm{IH}-2$ & $1500<\mathrm{IH} \leq 1800$ \\
\multirow{4}{*}{ Índice Heliotérmico } & Temperado & $\mathrm{IH}-1$ & $1800<\mathrm{IH} \leq 2100$ \\
& Temperado quente & $\mathrm{IH}+1$ & $2100<\mathrm{IH} \leq 2400$ \\
& Quente & $\mathrm{IH}+2$ & $2400<\mathrm{IH} \leq 3000$ \\
& Muito quente & $\mathrm{IH}+3$ & $3000<\mathrm{IH}$ \\
\hline & Noites quentes & $\mathrm{IF}-2$ & $18<\mathrm{IF}$ \\
Índice de Frio Noturno & Noites temperadas & $\mathrm{IF}-1$ & $14<\mathrm{IF} \leq 18$ \\
& Noites frias & $\mathrm{IF}+1$ & $12<\mathrm{IF} \leq 14$ \\
& Noites muito frias & $\mathrm{IF}+2$ & $\mathrm{IF} \leq 12$ \\
\hline \multirow{5}{*}{ Índice de Seca } & Úmido & $\mathrm{IS}-2$ & $150<\mathrm{IS}$ \\
& Subúmido & $\mathrm{IS}-1$ & $50<\mathrm{IS} \leq 150$ \\
& Seca moderada & $\mathrm{IS}+1$ & $-100<\mathrm{IS} \leq 50$ \\
& Muito seco & $\mathrm{IS}+2$ & $\mathrm{IS} \leq-100$ \\
\hline
\end{tabular}



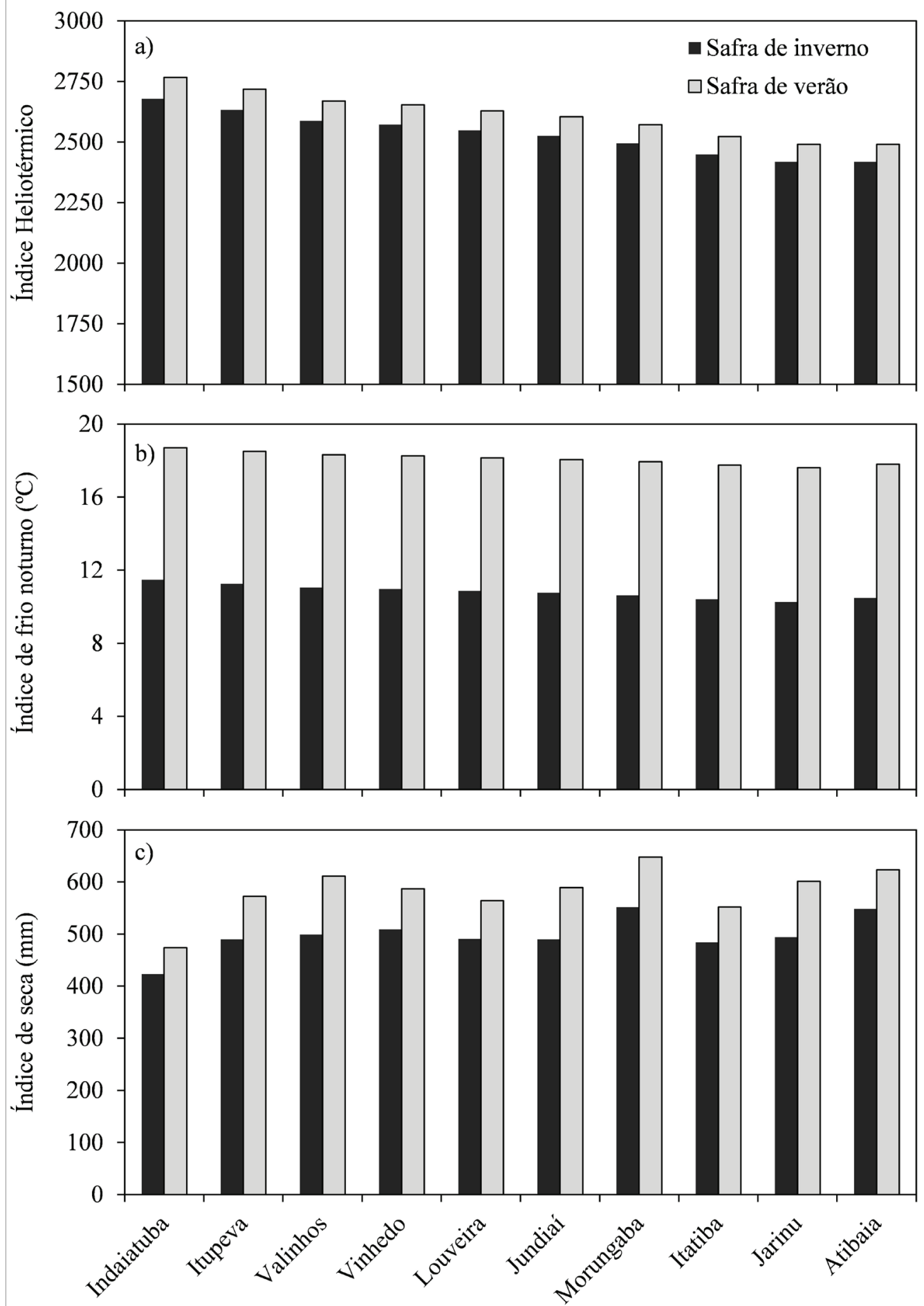

FIGURA 1 -Valores dos índices heliotérmico (a), de frio noturno (b) e de seca (c), safras de verão e de inverno, para os municípios do Circuito das Frutas, São Paulo. 


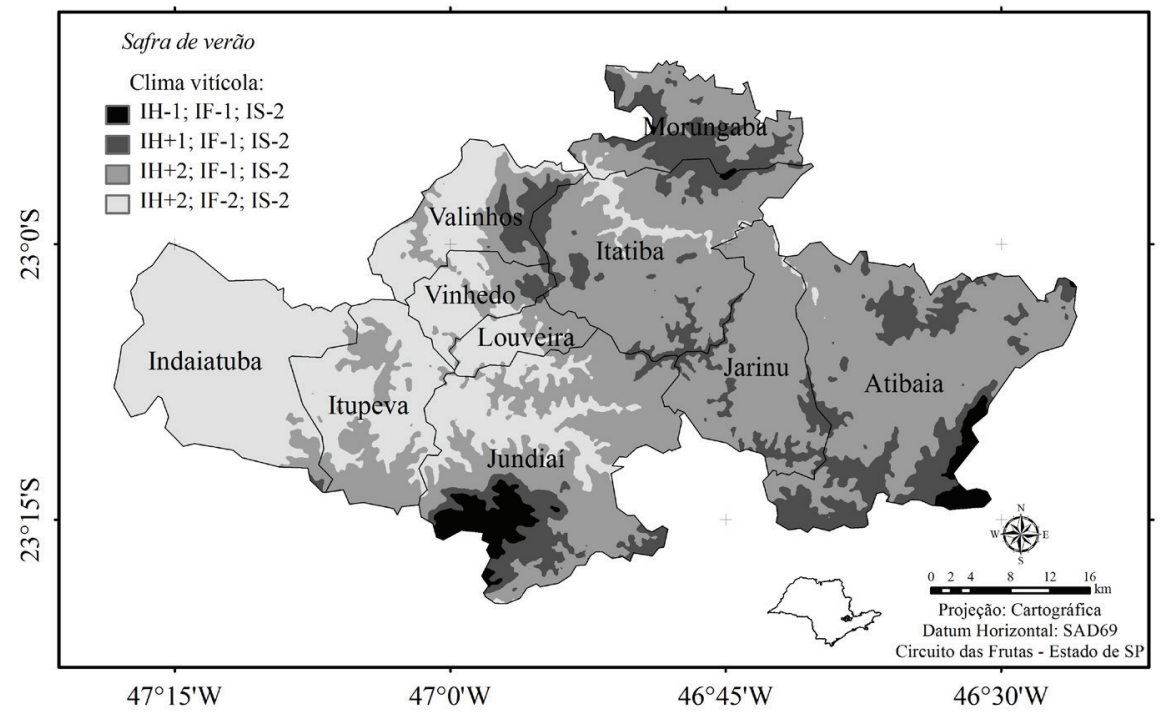

FIGURA2 - Espacialização do clima vitícola estimado por meio do Sistema CCM Geovitícola (TONIETTO; CARBONNEAU, 2004) para a região do Circuito das Frutas, Estado de São Paulo, safra de verão.

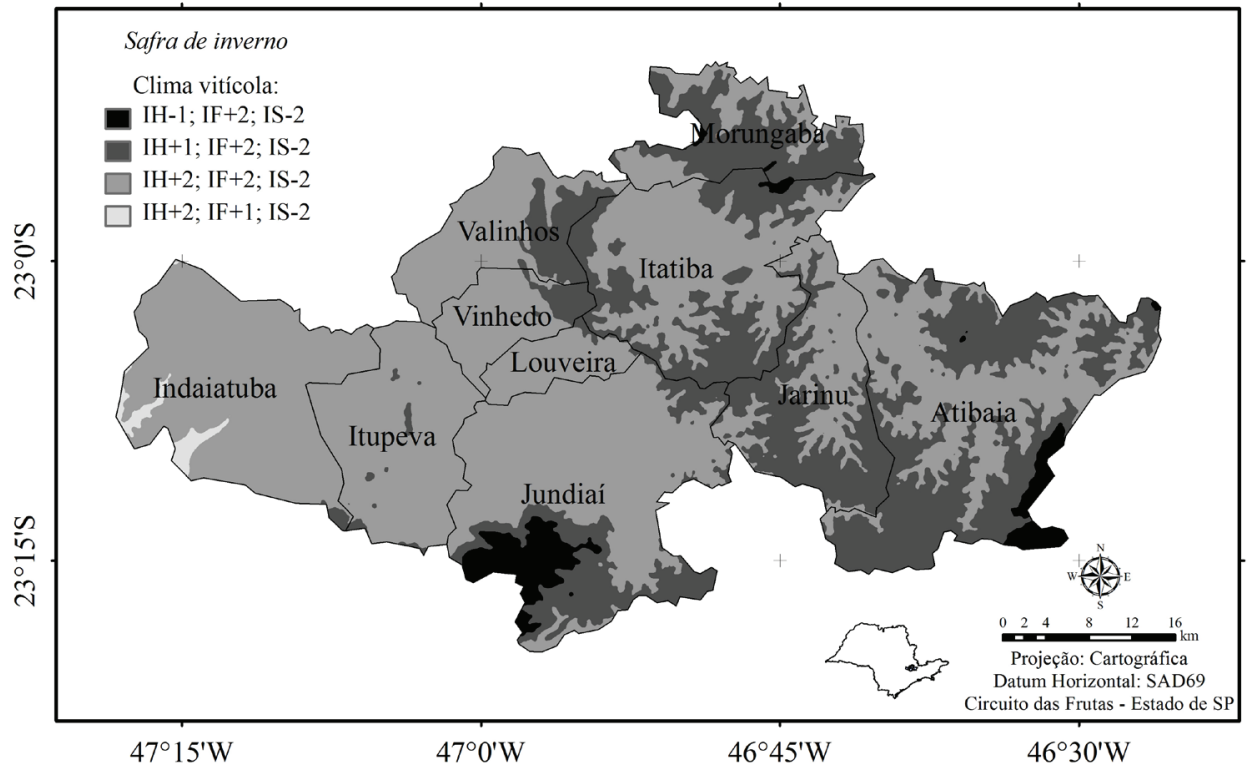

FIGURA 3 - Espacialização do clima vitícola estimado por meio do Sistema CCM Geovitícola (TONIETTO; CARBONNEAU, 2004) para a região do Circuito das Frutas, Estado de São Paulo, safra de inverno. 


\section{CONCLUSÕES}

Os municípios situados a oeste do Circuito das Frutas apresentaram, para as duas safras consideradas, valores do índice de Huglin mais elevados quando comparados aos situados na região leste.

O índice de frio noturno apresentou, para a safra de verão, valores mais baixos nas regiões de maiores altitudes; e para a safra de inverno, os valores do índice foram semelhantes para toda a região.

O índice de seca classificou o clima da região como úmido para ambas as safras.

Segundo o Sistema CCM Geovitícola, os climas vitícolas para a safra de verão foram: quente, temperado quente e temperado, com noites quentes ou temperadas, e úmido. Para a safra de inverno, entretanto, os valores do índice de seca mantiveramse elevados, com as seguintes classes de clima: quente, temperado quente e temperado, com noites muito frias.

\section{REFERÊNCIAS}

ALARCON, L.C.M.; MICHELLETO, D.; PORTAS, A.A.; BUENO, S.C.S. Implantação do vinhedo. In: BUENO, S.C.S. (Coord.). Vinhedo paulista. Campinas: CATI, 2010. p.55-86.

AMORIN, D.A.; FAVERO, A.C.; REGINA, M.A. Produção extemporânea da videira cultivar Syrah, nas condições do sul de Minas Gerais. Revista Brasileira de Fruticultura, Jaboticabal, v.27, n.2, p.327-331, 2005.

BARDIN, L.; PEDRO JÚNIOR, M.J.; MORAES, J.F.L. de. Risco climático de ocorrência de doenças fúngicas na videira 'Niágara Rosada' na região do Polo turístico do Circuito das Frutas do Estado de São Paulo. Bragantia, Campinas, v.69, n.4, p.10191026, 2010b.

BARDIN, L.; PEDRO JÚNIOR, M.J.; MORAIS, J.F.L. de. Estimativa das Temperaturas máximas e mínimas do ar para a região do Circuito das FrutasSP. Revista Brasileira de Engenharia Agrícola e Ambiental, Campina Grande, v.14, n.6, p.618-624, 2010a.

BOIS, B.; PÉRARD, J. Climat et viticulture au Vietnam: évalution et perspectives. Climatologie, v.6, v.1, p.75-89, 2009.
CARBONNEAU, A.; DELOIRE, A.; JAILLARD, B. La Vigne: physiologie, terroir, culture. Paris: Dunod Paris, 2007. 442p.

CAREY, V.A.; BONNARDOT, V. A viticultural perspective of meso $^{-}$scale atmospheric modelling in the Bottelaryberg-Simonsberg-Helderberg wine growing area (South Africa). Bulletin de l'Office International de la Vigne et du Vin, Paris, v.77, p. 20-46, 2004.

CONCEIÇÃO, M.A.F.; TONIETTO, J. Climatic potential for wine grape production in the tropical north region of Minas Gerais State, Brazil. Revista Brasileira de Fruticultura, Jaboticabal, v.27, n.3, p.404-407, 2005.

FÁVERO, A.C.; AMORIM, D.A.; MOTA, R.V.; SOARES, A.M.; REGINA, M.A. Viabilidade de produção da videira 'Syrah', em ciclo de outono inverno, na região de Minas Gerais. Revista Brasileira de Fruticultura, Jaboticabal, v.30, n.3, p.685-690, 2008.

HUGLIN, P. Nouveau mode d'évaluation des possibilities héliothermiques d'um milieu viticole. In: SYMPOSIUM INTERNATIONAL SUR L'ECOLOGIE DE LA VIGNE, 1978, Contança. Annales... Contança: Ministère de l'Agriculture et de l'Industrie Alimentaire, 1978. p.89-98.

JACKSON, D.I.; LOMBARD, P.B. Environmental and management practices affecting grape composition and wine quality: a review. American Journal of Enology and Viticulture, Davis, v. 44, v.4, p.409-430, 1993.

MARIN, F.R.; ASSAD, M.L.L.; PACHECO, L.R.F.; PILAU, F.G.; PINTO, H.S.; CONCEIÇÃO, M.A.F.; TONIETTO, J.; MANDELLI, F. Potencial de clima e solo para a viticultura, no estado de São Paulo. Revista Brasileira de Agrometeorologia, Santa Maria, v.16, n.2, p.163-174, 2008.

MOTA, R.V.; REGINA, M.A.; AMORIN, D.A.; FÁVERO, A.C. Fatores que afetam a maturação e a qualidade da uva para vinificação. Informe Agropecuário, Belo Horizonte, v.27, n.234, p. 5664, 2006. 
MOTA, R.V.; SILVA, C.P.C.S.; FAVERO, A.C.; PURGATTO, E.; SHIGA, T.M.; REGINA, M.A. Composição físico-química de uvas para vinho fino em ciclos de verão e inverno. Revista Brasileira de Fruticultura, Jaboticabal, v.32, n.4, p.1127-1137, 2010 .

POMMER, C.V.; MENDES, L.S.; HESPANHOVIANA, L.; BRESSAN-SMITH, R. Potencial climático para a produção de uvas em Campos dos Goytacazes, região norte fluminense. Revista Brasileira de Fruticultura, Jaboticabal,v.31, n.4, p.1076-1083, 2009.

SANTOS, A.O.; HERNANDES, J.L.; PEDRO JÚNIOR, M.J.; ROLIM, G.S. Parâmetros fitotécnicos e condições microclimáticas para videira vinífera conduzida sob dupla poda sequencial. Revista Brasileira de Engenharia Agrícola e Ambiental, Campina Grande, v.15, n.12, p.1251-1256, 2011 b.

SANTOS, A.O.; HERNANDES, J.L.; PEDRO JÚNIOR, M.P.; PEREIRA, S.E. Composição da produção e qualidade da uva em videira cultivada sob dupla poda e regime microclimático estacional contrastante. Revista Brasileira de Fruticultura, Jaboticabal, v.33, n.4, p.1135-1154, 2011a.

SANTOS, J.A.; MALHEIRO, A.C.; PINTO, J.G.; JONES, G.V. Macroclimate and viticultural zoning in Europe: observed trends and atmospheric forcing. Climate Research, Hertfordshire, v.51, n.1, p.89103, 2012.

SATO, G.S.; STREHLAU, V.; ALVES, H. S. Estratégias de mercado das vinícolas paulistas através de estudo de múltiplos casos. Informações Econômicas, São Paulo, v.40, n.4, p.70-85, 2010.

THORNTHWAITE, C.W. An approach toward a rational classification of climate. Geographical Review, New York, v.38, n.1, p.55-94, 1948.

TONIETTO J. Les macroclimats viticoles mondiaux et l'influence du mésoclimat sur la typicité de la Syrah et du Muscat de Hambourg dans le sud de la France:méthodologie de caractérisation. 1999. $233 \mathrm{f}$. Thèse (Doctorat) -École Nationale Supérieure Agronomique de Montpellier, Montpellier, 1999.
TONIETTO, J.; CARBONNEAU, A. A multicriteria climatic classification system for grape-growing regions worlwide. Agricultural and Forest Meteorology, Amsterdam, v.124, n.1/2, p.81-97, 2004.

TONIETTO, J.; RUIZ, V.S.; GÓMEZ-MIGUEL, V.D. Clima, zonificación y tipicidade del vino em regiones vitivinícolas iberoamericanas. Madrid: CYTED, 2012. 411p.

TONIETTO, J.; VIANELLO, R.L.; REGINA, M.A. Caracterização macroclimática e potencial enológico de diferentes regiões com vocação vitícola em Minas Gerais. Informe Agropecuário, Belo Horizonte, v.27, n.234, p.32-55, 2006.

VALERIANO, M.M. Topodata: guia de utilização de dados geomorfométricos locais. São José dos Campos: INPE, 2008.

VERDI, A.R.; OTANI, M.N.; MAIA, M.L.; FREDO, C.E.; OLIVERIA, A.L.R.; HERNADES, J.L. Panorama da vitivinicultura paulista, Censo 2009. Informações Econômicas, São Paulo, v.41, n.11, 2011.

WESTPhALEN, S. L.; MALUF, J. R. T. Caracterização das áreas bioclimáticas para 0 cultivo de Vitis vinífera $\mathbf{L}$. Regiões da serra do nordeste e planalto do estado do Rio Grande do Sul. Brasília: EMBRAPA, 2000. 98p. 